\title{
PIRÓLISE DE RESÍDUOS DO COCO-DA-BAÍA (Cocos nucifera Linn) E ANÁLISE DO CARVÃO VEGETAL ${ }^{1}$
}

\author{
Azarias Machado de Andrade ${ }^{2}$, Paulo Roberto de Assis Passos 3 , Luiz Guilherme da Costa Marques ${ }^{4}$, \\ Luciano Basto Oliveira ${ }^{4}$, Graziela Baptista Vidaurre ${ }^{5}$, José das Dores de Sá Rocha ${ }^{5}$
}

\begin{abstract}
RESUMO - Este trabalho objetivou realizar a pirólise de resíduos do coco-da-baía (Cocos nucifera Linn) e efetuar a análise química imediata do carvão vegetal produzido. Carvão vegetal, líquido pirolenhoso e gases não-condensáveis foram produzidos sob as temperaturas máximas de destilação de 350,450 e $550{ }^{\circ} \mathrm{C}$. Submeteramse à pirólise o coco inteiro e o seu endocarpo (verde e maduro), adotando como referência o carvão derivado do lenho de eucalipto (Eucalyptus urophylla S. T. Blake). O rendimento gravimétrico do carvão do coco inteiro, pirolisado na temperatura máxima de $350{ }^{\circ} \mathrm{C}$, foi estatisticamente superior aos dos demais tratamentos. Os maiores rendimentos em gases condensáveis foram obtidos a partir da pirólise do endocarpo verde, sob as três temperaturas máximas de pirólise analisadas. Os maiores teores de carbono fixo foram apresentados pelos carvões derivados do endocarpo do coco maduro, pirolisados nas temperaturas máximas de 450 e $550{ }^{\circ} \mathrm{C}$. Houve a equiparação estatística dos rendimentos em carbono fixo dos carvões do endocarpo do coco maduro e do lenho de eucalipto, pirolisados sob as três temperaturas máximas ora analisadas, e do coco inteiro destilado a 450 e $550{ }^{\circ} \mathrm{C}$.
\end{abstract}

Palavras-chave: Cocos nucifera, carvão vegetal, líquido pirolenhoso, destilação seca.

\section{PYROLYSIS OF COCONUT RESIDUES (Cocos nucifera L.) AND ANALYSIS OF CHARCOAL}

\begin{abstract}
The objective of this work was to carry out the pyrolysis of coconut residues (Cocos nucifera Linn) and to perform the chemical analysis of charcoal. Charcoal, pirogalyc liquid and non-condensed gases were produced under maximum temperatures of $350^{\circ} \mathrm{C}, 450^{\circ} \mathrm{C}$ and $550^{\circ} \mathrm{C}$. The whole coconut and its endocarp were pyrolysed (ripe and unripe), having as reference the charcoal derived from eucalyptus log (Eucalyptus urophylla S. T. Blake). The gravimetrical yield of whole coconut charcoal pyrolysed under maximum temperature of $350^{\circ} \mathrm{C}$, was superior to the other treatments. The largest yields of condensed gases were obtained from pyrolysis of unripe endocarp under the three pyrolysis temperatures. The highest levels of fixed carbon were given by charcoal derived from ripe endocarp, pyrolysed under maximum temperatures of $450^{\circ} \mathrm{C}$ and $550^{\circ} \mathrm{C}$. There was equal statistical response between fixed carbon yield from ripe endocarp charcoal and from eucalyptus log, pyrolysed in all the three maximum temperatures analyzed, and whole coconut pyrolysed under $450^{\circ} \mathrm{C}$ and $550^{\circ} \mathrm{C}$.
\end{abstract}

Key words: Cocos nucifera, charcoal, pirogalyc liquid, dry distillation.

\footnotetext{
${ }^{1}$ Recebido para publicação em 30.4.2003 e aceito para publicação em 10.8.2004

${ }^{2}$ DPF/IF/UFRRJ. 23890-000 Seropédica, RJ. <azarias@ufrrj.br>.

${ }^{3}$ IVIG/COPPE/UFRJ e CEFETEQ-RJ.

${ }^{4}$ IVIG/COPPE/UFRJ.

${ }^{5}$ Departamento de Engenharia Florestal da UFRRJ.
} 


\section{INTRODUÇÃO}

O coqueiro (Cocos nucifera Linn) é uma monocotiledônea pertencente à família Palmae e tem sua origem no sudeste asiático, nas ilhas entre os oceanos Índico e Pacífico. Acredita-se que, dessa região, o fruto do coqueiro tenha sido levado para a Índia e, em seguida, para o leste africano. Depois do descobrimento do Cabo de Boa Esperança, essa planta foi introduzida no oeste africano e, de lá, seguiu para as américas e para as demais regiões tropicais do globo terrestre (PURSEGLOVE, 1972).

Segundo Ferreira et al. (1998), o fruto do coqueiro é uma drupa, formada por uma epiderme lisa ou epicarpo, que envolve o mesocarpo espesso e fibroso, ficando mais no interior uma camada muito dura (pétrea), o endossarão. O fruto está envolto numa casca externa esverdeada ou amarelada que, com o tempo, tornase seca e castanha. Sob a casca, encontra-se uma camada de fibras com 3 a 5 cm de espessura. Santos (2002) citou que as fibras do coco se caracterizam pela sua dureza e durabilidade, atribuídas ao alto teor de lignina, em comparação com outras fibras naturais.

A cultura do coqueiro é importante na geração de renda, na alimentação e na produção de mais de 100 produtos, em mais de 86 países localizados na zona intertropical da terra. Em razão das suas inúmeras utilidades, o coqueiro é muitas vezes denominado "Árvore da Vida” (ERHARDT et al., 1976; FERREIRAet al., 1998).

O Brasil apresenta uma peculiaridade com relação ao fruto do coqueiro. Enquanto mundialmente o coco é conhecido como uma oleaginosa, sendo processado majoritariamente em seu estágio final de maturação para a produção de óleo e outros produtos, no país, o coco é consumido também imaturo para o aproveitamento da água rica em sais minerais, acumulada no seu interior (ROSA et al., 2001).

Nas cidades litorâneas e turísticas do Brasil podem ser obtidas grandes quantidades de coco verde descartados diariamente por comerciantes informais e por empresas que comercializam a parte comestível ou a água desse fruto. Segundo Rosa et al. (2001), a casca e as fibras correspondem a cerca de $90 \%$ do peso bruto do fruto. Para esses mesmos autores, a umidade média do coco verde, que pode chegar aos $85 \%$ (base úmida), bem como as propriedades das suas fibras, pode prejudicar algumas aplicações comuns ao fruto seco e, por isso, esse material é descartado como resíduo.
O fruto descartado, normalmente, é depositado nos aterros e nos denominados lixões. Isso tem provocado um significativo aumento nos serviços municipais de coleta, transporte e deposição de lixo em função, principalmente, do grande volume que representa. Devem-se considerar, também, a necessidade de grandes espaços nos vazadouros, o longo tempo de decomposição desse material (8 a 12 anos), os efeitos deletérios à paisagem urbana e os possíveis impactos negativos ao ambiente. De acordo com dados do IBGE (2003), estima-se que, do consumo em 2001, resultou 1,42 bilhão de cocos no Brasil. No Estado do Rio de Janeiro foram gerados 41,04 milhões de cocos, sendo 16,52 milhões somente na região metropolitana da cidade do Rio de Janeiro. Andrade et al. (2003) encontraram, em 100 cocos residuais verdes, um peso médio de $1415,71 \mathrm{~g} \pm 190 \mathrm{~g}$ por coco (coeficiente de variação $=13,42 \%$ ) e um porcentual de matéria absolutamente seca (base úmida) de 16,26\% $\pm 1 \%$ (coeficiente de variação $=6,15 \%$ ).

Para Valle (1995), um material deixa de ser considerado resíduo pela sua valorização como matériaprima para a produção de novos produtos. Nesse caso, determinado resíduo passa a ser tratado como subproduto do processo produtivo.

Atualmente, já existem algumas formas de aproveitamento do resíduo do coco, dentre as quais se destacam: as fibras do mesocarpo, com os seus diferentes comprimentos, servem para a produção de uma gama de produtos, como vestuário, sacarias, almofadas, colchões, acolchoados para a indústria automobilística, escovas, pincéis, cordas marítimas, cortiça isolante, xaxim ("coxim") para o cultivo de plantas etc. O endocarpo pode ser utilizado na produção de carvão para desodorização e ativado (FERREIRA et al., 1998). É possível a obtenção de compósitos a partir da mistura de PET reciclado e fibras de coco, com propriedades que permitem a sua utilização em vários setores (SANTOS, 2002). Outras formas de aproveitamento do resíduo do coco, que estão sendo aprimoradas no Estado do Rio de Janeiro, são: a produção de vasos, placas, tutores, substratos, adubo orgânico e material para isolamento termoacústico, sem a utilização de látex.

Em virtude das suas propriedades físicas e químicas, o coco verde residual pode ser queimado diretamente em fornalhas ou aproveitado para a produção de carvão vegetal. Segundo Nogueira et al. (2000), 
o poder calorífico superior (PCS) do coco residual é de cerca de $5.447,38 \mathrm{kcal} / \mathrm{kg}$ (base seca) e a composição elementar desse tipo de biomassa (base seca), de $48,23 \%$ de $\mathrm{C} ; 5,23 \%$ de $\mathrm{H} ; 33,19 \%$ de $\mathrm{O} ; 2,98 \%$ de $\mathrm{N} ; 0,12 \%$ de S; e $10,25 \%$ de outros elementos.

A partir da destilação seca desse material, além do carvão, poderão ser obtidas duas frações distintas, sendo uma constituída por substâncias condensáveis ("líquido pirolenhoso") e outra por gases incondensáveis. O líquido pirolenhoso apresenta inúmeras aplicações, dentre as quais se destacam o seu uso como fungicida, herbicida e inseticida, nas culturas orgânicas; como preservativo de madeira; como combustível líquido; como insumo para as indústrias química e farmacêutica; etc. Os gases incondensáveis, por sua vez, depois de serem armazenados por compressão em cilindros metálicos, podem ser utilizados como combustíveis gasosos para a geração de força-motriz e para a geração de energia térmica (ANDRADE e CARVALHO, 1998). O estabelecimento de novas formas de aproveitamento das sobras do coco-da-baía poderá reduzir o volume de resíduos sólidos nos aterros sanitários e proporcionar novas fontes de renda aos produtores, uma vez que as demandas atuais não consomem todo o coco descartado.

Os objetivos deste trabalho foram realizar a pirólise de resíduos do coco-da-baía (Cocos nucifera Linnn) e efetuar a análise química imediata do carvão vegetal produzido.

\section{MATERIAL E MÉTODOS}

\subsection{Matérias-primas (Cocos nucifera e Eucalyptus urophylla)}

No decorrer da pesquisa, desenvolvida no Laboratório de Energia da Madeira, do Instituto de Florestas, na Universidade Federal Rural do Rio de Janeiro (UFRRJ), foram utilizados frutos do coqueiro (Cocos nucifera) obtidos no comércio varejista da cidade de Seropédica e no próprio Campus da UFRRJ. Como testemunha foi usado o lenho de eucalipto (Eucalyptus urophylla), com sete anos de idade, de árvores coletadas num povoamento plantado em Seropédica, no Estado do Rio de Janeiro.

Os frutos do coqueiro, após terem os seus endocarpos (verde e maduro) separados, foram picados e postos a secar, primeiramente, ao ar livre e, em seguida, em uma estufa com circulação forçada de ar, regulada a $105^{\circ} \mathrm{C} \pm 3^{\circ} \mathrm{C}$, durante 48 horas. Procedi- mento de secagem semelhante foi adotado com relação aos cavacos obtidos do lenho de eucalipto. A Figura 1 apresenta o corte longitudinal de um coco, ilustrando as respectivas partes.

\subsection{Análises termogravimétricas dos materiais lignocelulósicos}

As destilações secas do coco inteiro, do endocarpo (verde e maduro) e do lenho de eucalipto foram conduzidas às temperaturas máximas de 350,450 e $550{ }^{\circ} \mathrm{C}$. Foram utilizadas amostras de aproximadamente $120 \mathrm{~g}$ de material seco em estufa regulada a 105 $\pm 3{ }^{\circ} \mathrm{C}$, durante 48 horas. No Quadro 1 constam os tratamentos analisados na presente pesquisa.

No decorrer das destilações secas, as amostras do material vegetal foram acondicionadas num cadinho metálico, apresentado na Figura 2, adaptado para liberar os gases e os vapores gerados durante o processo. Para a efetivação das destilações secas, o cadinho metálico foi colocado no interior de uma mufla elétrica, dotada de um termostato, para o controle da temperatura.

Tendo por base a matéria seca pirolisada, foram determinados os rendimentos gravimétricos em carvão e em carbono, além dos rendimentos em gases condensáveis, relacionando-se a massa do produto obtido com as correspondentes massas dos endocarpos, do coco inteiro ou do lenho do fuste de eucalipto. Os rendimentos em gases não-condensáveis foram obtidos subtraindo-se de $100 \%$ o somatório dos rendimentos gravimétricos em carvão e em gases condensáveis. Na Figura 3, apresenta-se o sistema que foi utilizado para a pirólise dos endocarpos (verde e maduro), de todo o fruto do coqueiro e do lenho de fustes de eucalipto (E. urophylla).

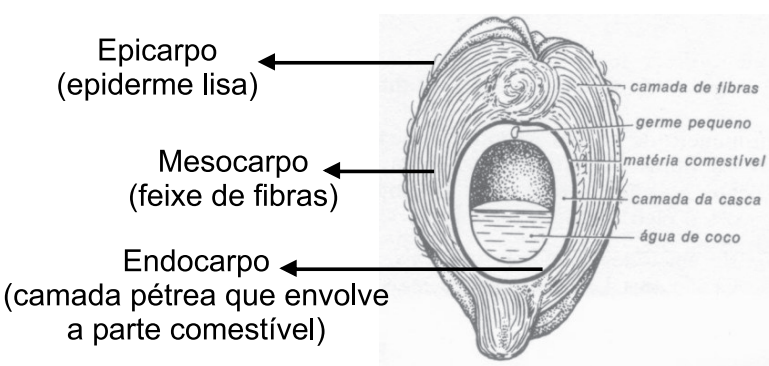

Figura 1 - Corte longitudinal do coco, com as suas partes (ERHARDT et al., 1976; FERREIRA et al., 1998).

Figure 1-Longitudinal cut of a coconut, with its parts (ERHARDT et al., 1976; FERREIRA et al., 1998).

R. Árvore, Viçosa-MG, v.28, n.5, p.707-714, 2004 
Quadro 1 - Tratamentos avaliados no decorrer das análises termogravimétricas dos endocarpos do coco-da-baía (C. nucifera), verde e maduro, do coco inteiro e do lenho de eucalipto (E. urophylla)

Table 1 - Treatments evaluated in elapsing of the termogravimetry analyses of green and mature coconut endocarps $(C$. Nucifera), entire coconut and E. urophylla

\begin{tabular}{cl}
\hline Tratamento & \multicolumn{1}{c}{ Especificação } \\
\hline 1 & Endocarpo verde, destilado na temperatura máxima de $350{ }^{\circ} \mathrm{C}$ \\
2 & Endocarpo verde, destilado na temperatura máxima de $450{ }^{\circ} \mathrm{C}$ \\
3 & Endocarpo verde, destilado na temperatura máxima de $550{ }^{\circ} \mathrm{C}$ \\
4 & Endocarpo maduro, destilado na temperatura máxima de $350{ }^{\circ} \mathrm{C}$ \\
5 & Endocarpo maduro, destilado na temperatura máxima de $450{ }^{\circ} \mathrm{C}$ \\
6 & Endocarpo maduro, destilado na temperatura máxima de $550{ }^{\circ} \mathrm{C}$ \\
7 & Coco inteiro, destilado na temperatura máxima de $350{ }^{\circ} \mathrm{C}$ \\
8 & Coco inteiro, destilado na temperatura máxima de $450{ }^{\circ} \mathrm{C}$ \\
9 & Coco inteiro, destilado na temperatura máxima de $550{ }^{\circ} \mathrm{C}$ \\
10 & Lenho de eucalipto, destilado na temperatura máxima de $350{ }^{\circ} \mathrm{C}$ \\
11 & Lenho de eucalipto, destilado na temperatura máxima de $450{ }^{\circ} \mathrm{C}$ \\
12 & Lenho de eucalipto, destilado na temperatura máxima de $550{ }^{\circ} \mathrm{C}$ \\
\hline
\end{tabular}

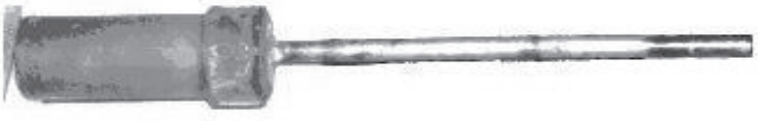

Figura 2 - Cadinho metálico usado na pirólise do material vegetal.

Figure 2 - Metallic recipient used during the pyrolysis of all materials.

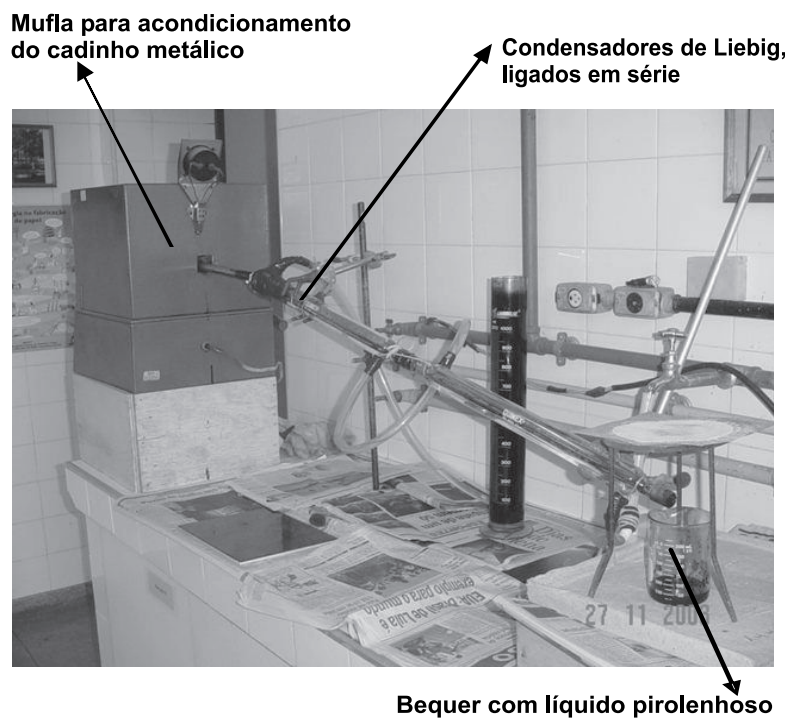

Figura 3 - Sistema laboratorial usado para a pirólise do material vegetal.

Figure 3 - System used for the pyrolysis of materials.
A análise química imediata do carvão foi efetuada com base na norma ASTM D-1762 - 64, adaptada para carvão vegetal por Oliveira et al. (1982), determinando-se os teores de material volátil, de cinza e de carbono fixado no carvão.

Para a análise dos dados relacionados às destilações secas foi adotado o delineamento experimental inteiramente casualizado, com 12 tratamentos e cinco repetições, dentro do esquema fatorial 4 x 3 , sendo quatro matérias-primas vegetais e três temperaturas máximas de destilação seca. A comparação estatística entre as médias dos tratamentos foi efetuada através do teste de Tukey, adotando-se o nível de $95 \%$ de probabilidade.

\section{RESULTADOS E DISCUSSÃO}

Os valores médios dos rendimentos gravimétricos em carvão (RGR), em gases condensáveis (RGC), em gases incondensáveis (RGI) e em carbono fixo (RCF), obtidos a partir da destilação seca dos endocarpos verdes e maduros, do coco inteiro ( $C$. nucifera) e do lenho de E. urophylla, nas temperaturas máximas de 350,450 e $550{ }^{\circ} \mathrm{C}$, são apresentados no Quadro 2.

Com relação ao que se apresenta no Quadro 2, podem-se fazer algumas inferências baseadas nos rendimentos gravimétricos em carvão. A média do rendimento gravimétrico em carvão vegetal apresentada pelo coco inteiro, destilado até a temperatura máxima de $350^{\circ} \mathrm{C}$, foi estatisticamente superior às demais. Num 
segundo plano aparecem os rendimentos gravimétricos em carvão apresentados pelo endocarpo maduro do coco-da-baía e pelo lenho de eucalipto (E. urophylla), destilados à temperatura máxima de $350^{\circ} \mathrm{C}$, seguidos pelo rendimento gravimétrico em carvão do coco inteiro e pelo lenho de eucalipto, destilados à temperatura máxima de $450^{\circ} \mathrm{C}$. Houve a equiparação dos rendimentos gravimétricos dos carvões oriundos dos endocarpos do coco (verde e maduro) e do coco inteiro com aqueles apresentados pelo carvão derivado do lenho de eucalipto. Em conformidade com os resultados obtidos por Andrade (1989), Andrade (1993) e Pereira et al. (2000), os maiores rendimentos gravimétricos em carvão foram aqueles relacionados às menores temperaturas de destilação. As reduções nos rendimentos gravimétricos em carvão resultam em aumentos nos rendimentos em gases condensáveis e, ou, incondensáveis.

Os rendimentos em gases condensáveis e incondensáveis estão estreitamente relacionados aos rendimentos gravimétricos em carvão. Um maior rendimento em carvão resultará em menor rendimento em gases condensáveis, incondensáveis ou ambos (ANDRADE, 1989; 1993). Na presente pesquisa, os maiores rendimentos em gases condensáveis foram obtidos a partir da destilação do endocarpo verde, em todas as temperaturas analisadas e da destilação do lenho de eucalipto a $550{ }^{\circ} \mathrm{C}$. Entretanto, no geral, os valores médios dos rendimentos em gases condensáveis e incondensáveis mantiveram-se em patamares aceitáveis do ponto de vista técnico-científico (PEREIRA et al., 2000). As variações observadas nesses valores deveram-se mais ao aumento gradativo da temperatura máxima de destilação e às conseqüentes oscilações dos rendimentos gravimétricos em carvão do material lignocelulósico.

Os maiores valores dos rendimentos em gases incondensáveis foram observados a partir da destilação dos endocarpos do coco (verde e maduro), destilados à temperatura máxima de $550^{\circ} \mathrm{C}$ e do coco inteiro em todas as temperaturas analisadas.

O rendimento em carbono fixo é o principal parâmetro a ser considerado por acasso da análise termogravimétrica de material lignocelulósico. O rendimento em carbono fixo envolve, simultaneamente, características de produtividade e de qualidade relacionadas ao carvão vegetal (ANDRADE, 1989; 1993). No que tange à presente pesquisa, observou-se a equiparação estatística dos rendimentos em carbono fixo dos carvões do endocarpo do coco maduro e do lenho de eucalipto, destilados sob as três temperaturas máximas ora analisadas e do coco inteiro destilado a 450 e a $550^{\circ} \mathrm{C}$.

Quadro 2 - Valores médios dos rendimentos gravimétricos em carvão (RGR), em gases condensáveis (RGC), em gases incondensáveis (RGI) e em carbono fixo (RCF), obtidos a partir da destilação seca dos endocarpos verdes e maduros, do coco inteiro (C. nucifera) e do lenho de E. urophylla, nas temperaturas máximas de 350,450 e $550{ }^{\circ} \mathrm{C}^{*}$

Table 2 - Average values of the gravimetrical incomes in coal, in condensed gases, incondensed gases and fixed carbon, gotten from the dry destillation of green and mature cocunut endocarps, entire coconut and E. urophylla, under maximum temperatures of 350,450 and $550^{\circ} \mathrm{C}$

\begin{tabular}{lllll}
\hline \multicolumn{1}{c}{ Tratamento } & RGR $(\%)$ & RGC $(\%)$ & RGI $(\%)$ & RCF $(\%)$ \\
\hline 1 - Endocarpo verde a $350{ }^{\circ} \mathrm{C}$ & $29,54 \mathrm{~d}$ & $45,89 \mathrm{a}$ & $24,57 \mathrm{~cd}$ & $20,49 \mathrm{~d}$ \\
2 - Endocarpo verde a $450{ }^{\circ} \mathrm{C}$ & $30,67 \mathrm{~cd}$ & $45,62 \mathrm{a}$ & $23,70 \mathrm{~d}$ & $22,31 \mathrm{~cd}$ \\
3 - Endocarpo verde a $550^{\circ} \mathrm{C}$ & $26,41 \mathrm{e}$ & $43,51 \mathrm{ab}$ & $30,08 \mathrm{ab}$ & $21,33 \mathrm{~d}$ \\
4 - Endocarpo maduro a $350{ }^{\circ} \mathrm{C}$ & $32,75 \mathrm{~b}$ & $42,27 \mathrm{bc}$ & $24,98 \mathrm{~cd}$ & $24,27 \mathrm{ab}$ \\
5 - Endocarpo maduro a $450{ }^{\circ} \mathrm{C}$ & $30,67 \mathrm{~cd}$ & $41,86 \mathrm{bcd}$ & $27,46 \mathrm{bc}$ & $25,75 \mathrm{a}$ \\
6 - Endocarpo maduro a $550{ }^{\circ} \mathrm{C}$ & $29,34 \mathrm{~d}$ & $41,58 \mathrm{bcd}$ & $29,07 \mathrm{ab}$ & $26,17 \mathrm{a}$ \\
7 - Coco inteiro a $350{ }^{\circ} \mathrm{C}$ & $34,31 \mathrm{a}$ & $34,53 \mathrm{e}$ & $31,15 \mathrm{a}$ & $23,56 \mathrm{bc}$ \\
8 - Coco inteiro a $450{ }^{\circ} \mathrm{C}$ & $32,13 \mathrm{bc}$ & $39,41 \mathrm{~cd}$ & $28,45 \mathrm{ab}$ & $25,25 \mathrm{ab}$ \\
9 - Coco inteiro a $550{ }^{\circ} \mathrm{C}$ & $30,55 \mathrm{~d}$ & $38,91 \mathrm{~d}$ & $30,52 \mathrm{ab}$ & $24,71 \mathrm{ab}$ \\
10 - E. urophylla a $350{ }^{\circ} \mathrm{C}$ & $33,21 \mathrm{~b}$ & $41,48 \mathrm{bcd}$ & $25,31 \mathrm{~cd}$ & $25,24 \mathrm{ab}$ \\
11 - E. urophylla a $450{ }^{\circ} \mathrm{C}$ & $31,59 \mathrm{bc}$ & $41,00 \mathrm{bcd}$ & $27,41 \mathrm{bc}$ & $25,59 \mathrm{a}$ \\
12 - E. urophylla a $550{ }^{\circ} \mathrm{C}$ & $27,80 \mathrm{e}$ & $45,20 \mathrm{a}$ & $27,00 \mathrm{bc}$ & $24,85 \mathrm{ab}$ \\
\hline
\end{tabular}

*Médias seguidas da mesma letra na coluna não diferem estatisticamente entre si, pelo teste de Tukey a 95\% de probabilidade. 
Os valores médios resultantes das análises químicas imediatas dos carvões dos endocarpos do coco (verde e maduro), do coco inteiro e do lenho do eucalipto constam no Quadro 3.

A observação dos teores médios de matéria volátil dos carvões indica que eles foram mais influenciados pela temperatura máxima de destilação do que pela matéria-prima propriamente dita. De forma geral e do ponto de vista estatístico, correlações negativas são percebidas entre os teores de matéria volátil dos carvões e nas temperaturas máximas de destilação seca, ou seja, quanto menor a temperatura de destilação seca, maior o teor de matéria volátil no carvão vegetal. Isso ocorre independentemente do material lignocelulósico que está sendo submetido à destilação seca (ANDRADE, 1993; ANDRADE e CARVALHO, 1998). Todavia, do ponto de vista estritamente absoluto, os teores médios de matéria volátíl dos carvões derivados do material lignocelulósico ora analisados mantiveram-se em patamares bastante próximos, dentro das respectivas temperaturas máximas de destilação. Foram altos os teores de cinza apresentados pelos carvões derivados do endocarpo verde e do coco inteiro. Quando comparados com os teores de cinza apresentados pelos carvões derivados do endocarpo maduro e do lenho do eucalipto foram detectados, em média, valores cerca de 10 vezes maiores nos teores de cinza do carvão do endocarpo verde e do coco inteiro. Isso deve ser considerado como um fator negativo, uma vez que teores elevados de cinza provocam reduções nos teores de carbono fixado no carvão vegetal.

Do ponto de vista estatístico, os maiores teores de carbono fixo foram apresentados pelos carvões derivados do endocarpo maduro, destilado às temperaturas máximas de 450 e de $550^{\circ} \mathrm{C}$ e pelo carvão do lenho de eucalipto, destilado à temperatura de 550 ${ }^{\circ} \mathrm{C}$. Ainda do ponto de vista estatístico, os menores teores de carbono fixo foram apresentados pelos carvões dos endocarpos (verde e maduro) e do coco inteiro, destilados à temperatura máxima de $350^{\circ} \mathrm{C}$, bem como pelo carvão do endocarpo verde destilado a $450{ }^{\circ} \mathrm{C}$. Confirmou-se, portanto, conforme enunciado por Andrade (1989), Andrade (1993), Andrade e Carvalho (1998) e Nogueira et al. (2000), uma correlação positiva entre os teores de carbono fixo e as temperaturas máximas de destilação.

\section{CONCLUSÕES}

Com base nos resultados observados, chegouse às seguintes conclusões:

Quadro 3 - Valores médios dos teores de matérias voláteis (TMV), de cinza (TCZ) e de carbono fixo (TCF) dos carvões dos endocarpos (verde e maduro), do coco inteiro (C. nucifera) e do lenho do eucalipto (E. urophylla), produzidos nass temperaturas máximas de 350,450 e $550^{\circ} \mathrm{C} *$

Table 3 - Average values of volatile substances, ash and fixed carbon of the coals of the endocarps (green and mature), entire coconut and E. urophylla, produced under maximum temperatures of to 350,450 and $550{ }^{\circ} \mathrm{C}$

\begin{tabular}{lccc}
\hline \multicolumn{1}{c}{ Tratamento } & TMV $(\%)$ & TCZ $(\%)$ & TCF (\%) \\
\hline 1 - Endocarpo verde a $350{ }^{\circ} \mathrm{C}$ & $22,20 \mathrm{a}$ & $6,70 \mathrm{ab}$ & $70,80 \mathrm{~d}$ \\
2 - Endocarpo verde a $450{ }^{\circ} \mathrm{C}$ & $17,60 \mathrm{~b}$ & $11,10 \mathrm{a}$ & $71,50 \mathrm{~d}$ \\
3 - Endocarpo verde a $550{ }^{\circ} \mathrm{C}$ & $10,20 \mathrm{c}$ & $10,30 \mathrm{a}$ & $79,70 \mathrm{bc}$ \\
4 - Endocarpo maduro a $350{ }^{\circ} \mathrm{C}$ & $25,25 \mathrm{a}$ & $0,50 \mathrm{c}$ & $74,25 \mathrm{~cd}$ \\
5 - Endocarpo maduro a $450{ }^{\circ} \mathrm{C}$ & $14,50 \mathrm{bc}$ & $1,75 \mathrm{c}$ & $83,75 \mathrm{ab}$ \\
6 - Endocarpo maduro a $550{ }^{\circ} \mathrm{C}$ & $9,75 \mathrm{c}$ & $1,25 \mathrm{c}$ & $89,00 \mathrm{a}$ \\
7 - Coco inteiro a $350{ }^{\circ} \mathrm{C}$ & $22,75 \mathrm{a}$ & $8,50 \mathrm{ab}$ & $79,75 \mathrm{~d}$ \\
8 - Coco inteiro a $450{ }^{\circ} \mathrm{C}$ & $12,25 \mathrm{c}$ & $8,50 \mathrm{ab}$ & $81,00 \mathrm{bc}$ \\
9 - Coco inteiro a $550{ }^{\circ} \mathrm{C}$ & $12,50 \mathrm{c}$ & $76,00 \mathrm{c}$ \\
10 - E. urophylla a $350{ }^{\circ} \mathrm{C}$ & $23,00 \mathrm{a}$ & $7,25 \mathrm{ab}$ & $81,00 \mathrm{bc}$ \\
11 - E. urophylla a $450{ }^{\circ} \mathrm{C}$ & $18,00 \mathrm{~b}$ & $1,00 \mathrm{c}$ & $89,40 \mathrm{a}$ \\
12 - E. urophylla a $550{ }^{\circ} \mathrm{C}$ & $9,60 \mathrm{c}$ & $1,00 \mathrm{c}$ & $1,00 \mathrm{c}$ \\
\hline
\end{tabular}

*Médias seguidas da mesma letra na coluna não diferem estatisticamente entre si, pelo teste de Tukey a 95\% de probabilidade. 
1. O fruto do coqueiro ( C. nucifera) presta-se para a produção de um carvão vegetal com uma boa produtividade e uma boa qualidade, bem como para a geração de subprodutos da carbonização.

2. Ao visar à produtividade em carvão vegetal sem atentar, por exemplo, para o poder calorífico do carvão, deve-se optar pelo uso do coco inteiro, destilado à temperatura máxima de $350^{\circ} \mathrm{C}$, cujo rendimento gravimétrico médio $(34,31 \%)$ foi estatisticamente superior aos dos demais tratamentos.

3. Ao visar à qualidade do carvão vegetal sem, contudo, atentar para a produtividade em carvão, devese optar pelo uso do endocarpo do coco maduro, destilado à temperatura máxima de $450^{\circ} \mathrm{C}$, cujo teor médio de carbono fixo se equiparou àquele apresentado pelo carvão do lenho de eucalipto (E. urophylla), destilado à temperatura máxima de $550^{\circ} \mathrm{C}$.

4. Ao visar, simultaneamente, à produtividade e qualidade do carvão vegetal, deve-se optar pelo endocarpo do coco maduro, destilado à temperatura máxima de $350{ }^{\circ} \mathrm{C}$ ou pelo coco inteiro, destilado a 450 ${ }^{\circ} \mathrm{C}$. Os rendimentos médios em carbono fixo, nesses casos, equipararam-se àqueles apresentados pelos carvões derivados do lenho do eucalipto (E. urophylla).

5. O carvão vegetal derivado do coco inteiro, em virtude dos bons rendimentos gravimétricos apresentados (30,55 a 34,31\%), embora ainda sejam necessários estudos específicos, possivelmente poderá ser usado como insumo energético em fornalhas de cerâmicas, de padarias e de pizzarias, dentre outras aplicações afins. Esse carvão, entretanto, não parece indicado para fins siderúrgicos.

\section{AGRADECIMENTOS}

Ao Instituto Virtual Internacional de Mudanças Globais (IVIG/COPPE/UFRJ), representado por seu Coordenador Geral Professor Luiz Pinguelli Rosa, pelo apoio técnico-científico e pela concessão de duas bolsas de iniciação científica.

\section{REFERÊNCIAS BIBLIOGRÁFICAS}

ANDRADE, A.M. et al. Produção de compósitos de pasta de papel velho com Coco da Bahia (Cocos nucifera Linn) triturado. Rio de Janeiro: Universidade Federal Rural do Rio de Janeiro, convênio UFRRJ / COPPE - UFRJ, 2003. 47 p. (Relatório Final, não-publicado)
ANDRADE, A.M. Efeitos da fertilização mineral e da calagem na produção e na qualidade da madeira e do carvão de eucalipto. 1993. 105 f. Tese (Doutorado em Ciência Florestal) - Universidade Federal de Viçosa, Viçosa, 1993.

ANDRADE, A.M. Influência da casca de Eucalyptus grandis W.Hill ex Maiden no rendimento e qualidade de carvão vegetal. 1989. 86 f. Dissertação (Mestrado em Ciência Florestal) - Universidade Federal de Viçosa, Viçosa, 1989.

ANDRADE, A.M.; CARVALHO, L.M.

Potencialidades energéticas de oito espécies florestais do Estado do Rio de Janeiro. Floresta e Ambiente, v.5, n.1, p. 24-42, 1998.

ERHARDT, T. et al. Curso Técnico Têxtil Física e Química Aplicada - Fibras Têxteis - Tecnologia. São Paulo: Pedagógica e Universitária Ltda / EDUSP; Universidade de São Paulo, 1976.88 p. v.1.

FERREIRA, J.M.S.; WARWICK, D.R.N.; SIQUEIRA.; L.A. A cultura do coqueiro no Brasil. 2. ed. Brasília: EMBRAPA-SPI, 1998. 292 p.

INSTITUTO BRASILEIRO DE GEOGRAFIA E estatísticA - IBGE. Banco de Dados Agregados. Brasília, DF: PAM - Produção Agrícola dos Municípios. Disponível em: http:// www.ibge.org.br. Acesso em: 26 de novembro de 2003.

NOGUEIRA, L.A.H. et al. Dendroenergia: fundamentos e aplicações. Brasília, DF: ANEEL - Agência Nacional de Energia Elétrica, 2000. 144 p.

OLIVEIRA, J.B.; GOMES, P.A.; ALMEIDA, M.R. Carvão vegetal - destilação, carvoejamento, propriedades e controle de qualidade. Belo Horizonte: CETEC - Centro Tecnológico de Minas Gerais, 1982. $173 \mathrm{p}$.

R. Árvore, Viçosa-MG, v.28, n.5, p.707-714, 2004 
PEREIRA, J.C.D. et al. Características da madeira de algumas espécies de eucalipto plantadas no Brasil. Colombo: Embrapa Florestas, 2000. 113 p. (Embrapa Florestas. Documentos, 38).

PURSEGLOVE, J.W. Tropical crops monocotyledos. London: Longman, 1972. $607 \mathrm{p}$.

ROSA, M.F. et al. Processo agroindustrial: obtenção de pó de casca de coco verde. Fortaleza: EMBRAPA, 2001. não paginado. (Comunicado Técnico).
SANTOS, M. S. Propriedades térmicas e mecânicas de materiais reciclados a base de PET pós consumo e cargas de coco. 2002. 85 f. Dissertação (Mestrado em Ciência e Tecnologia de Polímeros). Universidade Federal do Rio de Janeiro, Rio de Janeiro, 2002.

VALLE, C.E. Qualidade ambiental: o desafio de ser competitivo protegendo o meio ambiente. São Paulo: Pioneira, 1995. não paginado. 